\title{
A SURVEY OF THE PREVALENCE OF LEG WEAKNESS IN SWEDISH BROILER CHICKENS - A PILOT STUDY
}

\author{
Berg, C. ${ }^{1}$ and Sanotra, G.S. ${ }^{2}$ \\ 1Dept. of Animal Environment and Health, Swedish University of Agricultural Sciences, P.O. Box 234, \\ SE - 53223 Skara, Sweden \\ ${ }^{2}$ Dept. of Animal Science and Animal Health, The Royal Veterinary and Agricultural University, \\ Grønnegårdsvej 8, DK- 1870 Frederiksberg C, Copenhagen, Denmark.
}

The general term "leg weakness" in broilers usually refers to joint problems in hips, knees or intertarsal joints. Tibial chondrodysplasia (TD) is considered to be the most common disorder but also other forms of developmental disturbances, deformities and infections and may occur (Lynch et al., 1992). TD is linked to the rapid growth rate of the birds and is influenced by the birds' genetic background and by nutrition, housing and management. Severe leg weakness, regardless of the cause, will lead to considerable difficulties in walking which will make it difficult for the birds to reach feed and water, and the lesions are also considered as painful to the birds (Danbury et al., 2000).

The prevalence of leg weakness in Swedish broilers was surveyed in a pilot study encompassing a total of eight flocks from four different farms. This was done by a type of visual assessment of the birds' walking ability, known as gait scoring (Kestin et al., 1992). At the same occasion the birds were weighed and sexed, and the position of their legs and the foot health evaluated. All flocks were of mixed sexes and consisted of the same commercial hybrid. A total of 50 birds per flock were scored during the last week before slaughter (29-33 days of age).

The results show that $36.5 \%$ of the birds had a fully normal gait (gait score 0 ), $48.8 \%$ had a slight defect or a mildly affected gait (gait score 1-2), 13.5\% had a moderately but obviously disturbed gait pattern where manoeuvrability, acceleration or speed was affected (gait score 3), and 1.3\% showed severe disorders (gait score 4). No bird that was incapable of sustained walking (gait score 5) was found. Angular limb deformities (varus/valgus) were found in $20.8 \%$ of the birds, and there was a significant correlation between this type of deformities and the prevalence of leg weakness (defined as gait score 3 or higher) and the birds' body weight. Considerable differences in the prevalence of leg weakness between the different farms and also between different compartments/flocks within the same farm were found.

It is concluded that the prevalence of leg problems (gait score $\geq 3$ ) in the flocks studied was approx. $15 \%$ and that further research to identify the main risk factors under current management practices will be necessary to minimize these problems.

\section{References}

Kestin SC, Knowles TG, Tinch AE \& Gregory NG. Prevalence of leg weakness in broiler chickens and its relationship with genotype. Vet Rec 1992, 131: 190-194.

Danbury TC, Weeks CA, Chambers JP, Waterman-Pearson AE \& Kestin SC. Self-selection of the analgesic drug carprofen by lame broiler chickens. Vet Rec 2000,146: 307-311.

Lynch M, Thorp BH \& Whitehead CC. Avian tibial dyschondroplasia as a cause of bone deformity. Avian Path 1992, 2: 275 . 